\title{
Evaluation of Head Computed Tomography Assessment of Brain Swelling after Acute Traumatic Brain Injury: A Pilot study
}

\section{Avaliação da tomografia computadorizada de crânio com edema cerebral após lesão cerebral traumática aguda: Um estudo piloto}

\author{
Robson Luis Amorim ${ }^{1}$ Barbara Albuquerque Morais ${ }^{1}$ Francisco Otávio Camargo Pereira ${ }^{2}$ \\ Matheus Fernandes Oliveira ${ }^{1}$ Almir Ferreira Andrade ${ }^{1} \quad$ Edson Bor-Seng-Shu $^{1}$ Marcelo Lima Oliveira ${ }^{1}$ \\ Manoel Jacobsen Teixeira ${ }^{1}$ Wellingson Silva Paiva ${ }^{1}$
}

${ }^{1}$ Division of Neurosurgery, Faculdade de Medicina, Universidade de São Paulo, São Paulo, SP, Brazil

${ }^{2}$ Division of Neurosurgery, Universidade do Estado de São Paulo, Botucatu, SP, Brazil

Address for correspondence Matheus Fernandes de Oliveira, PhD, Rua Loefgren 700, apto 103, Vila Clementino, São Paulo, 04040-000, Brazil (e-mail: mafernoliv@yahoo.com.br).

Arq Bras Neurocir 2019;38:257-262.

\section{Abstract \\ Keywords \\ - brain injurytraumatic \\ - tomography \\ - critical care \\ - prognosis}

Resumo
Objective To evaluate the interobserver reliability of a new scale created for quantitatively assessing brain swelling in traumatic brain injury (TBI) patients using the computed tomography (CT) findings in three levels.

Methods Computed tomography scans of severe head injury patients were randomly selected from a tertiary hospital image database and evaluated by independent groups of neurosurgeons, neurosurgery residents, radiologists, and intensivists from the same hospital. Each specialist assessed the tomographic findings, applying zero to six points in a new scale. The Kappa coefficient was calculated to assess interobserver agreement. Results The highest reliability coefficient was obtained by the neurosurgeons group (0.791; 95\% confidence interval $[\mathrm{Cl}]: 0.975-0.607 ; p<0.001)$, followed by the neurosurgery residents group $(0.402 ; 95 \% \mathrm{Cl}: 0.569-0.236 ; p<0.001)$ and by the radiologists group $(0.301 ; 95 \% \mathrm{Cl}: 0.488-0.113 ; p<0.002)$. The lowest coefficient was found among the intensivists $(0.248 ; 95 \% \mathrm{Cl}: 0.415-0.081 ; p=0.004)$.

Conclusion The proposed scale showed good reliability among neurosurgeons, and moderate overall reliability. This tomographic classification might be useful to better assist severe TBI victims, allowing to identify the worsening or amelioration of brain swelling, which should be further investigated. The scale seems to be feasible, even in low income countries, where the cost of intracranial pressure (ICP) monitoring is higher than that of CTs.

Objetivo Avaliar a confiabilidade interobservador de uma nova escala criada para avaliar quantitativamente o edema cerebral em pacientes com trauma cranioencefálico (TCE) utilizando os achados de tomografia computadorizada (TC) em três níveis. received

May 12, 2019

accepted

August 6, 2019
DOI https://doi.org/

10.1055/s-0039-1698785. ISSN 0103-5355.
Copyright (e 2019 by Thieme Revinter

Publicações Ltda, Rio de Janeiro, Brazil
License terms

(c) (i) $\ominus$ (\$) 


$\begin{array}{ll} & \text { Métodos Tomografias computadorizadas de pacientes com TCE grave foram sele- } \\ & \text { cionadas aleatoriamente a partir de um banco de imagens de hospitais terciários e } \\ \text { avaliadas por grupos independentes de neurocirurgiões, residentes de neurocirurgia, } \\ \text { radiologistas e intensivistas do mesmo hospital. Cada especialista avaliou os achados } \\ \text { tomográficos, aplicando zero a seis pontos em uma nova escala. O coeficiente Kappa foi } \\ \text { calculado para avaliar a concordância interobservador. } \\ \text { Resultados O maior coeficiente de confiabilidade foi obtido pelo grupo de neuroci- } \\ \text { rurgiões (0,791, intervalo de confiança [IC] de } 95 \%: 0,975-0,607 ; p<0,001) \text {, seguido } \\ \text { pelo grupo de residentes de neurocirurgia }(0,402 ; \text { IC95\%: } 0,569-0,236 ; p<0,001) \text { e o } \\ \\ \text { grupo de radiologistas (0,301; IC } 95 \% 0,488-0,113 ; p<0,002) \text {. O menor coeficiente foi } \\ \text { Palavras-chave } & \text { encontrado entre os intensivistas }(0,248 ; \text { IC95\%: } 0,415-0,081 ; p=0,004) \text {. } \\ \text { - lesão cerebral } & \text { Conclusão A escala proposta mostrou boa confiabilidade entre os neurocirurgiões e } \\ \text { - traumática } & \text { moderada confiabilidade geral. Essa classificação tomográfica pode ser útil para auxiliar } \\ \text { - tomografia } & \text { melhor as vítimas graves de TCE, permitindo identificar o agravamento ou melhoria do } \\ \text { - tratamento crítico } & \text { inchaço cerebral, que deve ser mais investigado. A escala parece ser viável, mesmo em } \\ \text { - prognóstico } & \text { países de baixa renda, onde o custo da monitoração da pressão intracraniana (PIC) é } \\ & \text { maior que o dos TCs. }\end{array}$

\section{Introduction}

Traumatic brain injury (TBI) is a major cause of death and morbidity among young adults, and many studies investigate prediction factors of mortality among these patients. ${ }^{1}$ The severity of these lesions is increasing in developing countries. ${ }^{2,3}$ One of the most devastating consequences of severe TBI is brain swelling, which results from either vascular engorgement or accumulation of excessive fluid in the intraor extracellular space. ${ }^{4}$ Brain swelling follows the increase of intracranial pressure (ICP), occurring in $16 \%$ of all TBI victims ${ }^{5}$ and in $28 \%$ of pediatric head-injured patients. ${ }^{6}$

Unfortunately, even in high-income countries, ICP monitoring via a fiber optic monitor or via an adaptable external ventricular drain (EVD) system is not performed in every patient, ${ }^{7}$ highlighting a problem on how to manage these patients. A controlled trial ${ }^{8}$ comparing pressure monitoring with clinical evaluation and imaging by computed tomography (CT) scans has shown similar outcomes. In fact, in day-to-day practice, when the trauma team faces a patient without ICP monitoring, the use of serial CT scans (a widely available imaging tool in emergency rooms) might help the management of sedation or adjusting therapeutic intensity levels. Although CT scan findings of effacement of cortical sulci and cisterns are described as prognostic variables in some studies, ${ }^{8,9}$ the usefulness of $\mathrm{CT}$ in the management of TBI patients is rarely described, probably because these variables are often assessed subjectively.

Moreover, the tomographic scales available $e^{10,11}$ are assessed only to predict outcomes, and they have no role in guiding the therapy of brain swelling in the emergency room or in the intensive care units (ICUs). To our knowledge, there are no radiologic scales to assess the dynamic changes that may occur on the brain following TBI. Therefore, a tomographic classification system that allows the quantifi- cation of brain swelling and the comparison between the features of the exams is of great importance.

In the present study, the authors propose to evaluate the interobserver reliability of a new scale proposed to analyze traumatic brain swelling by using $\mathrm{CT}$, which takes into consideration the status of the sylvian fissure and of the cortical sulci.

\section{Methods}

\section{Study Design and Participants}

This is a diagnostic accuracy study of interobserver reliability evaluation of CT scans of severe TBI patients showing brain swelling, in victims $>16$ years old admitted in the emergency service of a public hospital for the management of closed severe TBI.

Tomographic findings of focal injuries requiring surgical intervention (hematoma volume $>25 \mathrm{cc}$ ) and midline shift $>5 \mathrm{~mm}$ were excluded from the sample. The CT scans made up to 35 minutes after the arrival at the hospital, after all life support and/or resuscitation measures had been applied, were compared with CT scans randomly selected in a tertiary hospital database for the calculation of interobserver agreement. A total of 20 brain CT scans were randomly selected (using the Web site random.org for generating sequential medical record numbers) from the image database of the hospital (Philips iSite PACS; Philips, Amsterdam, Netherlands) to be used in the present study.

\section{Ethics}

Prior approval by an ethical committee was waived in the present study (protocol number 00119/10), because it was entirely based on medical records and archival images. The participants in the present investigation were all physicians and they had no contact with the patients for the evaluations made, only with archival material. Still, confidentiality was 


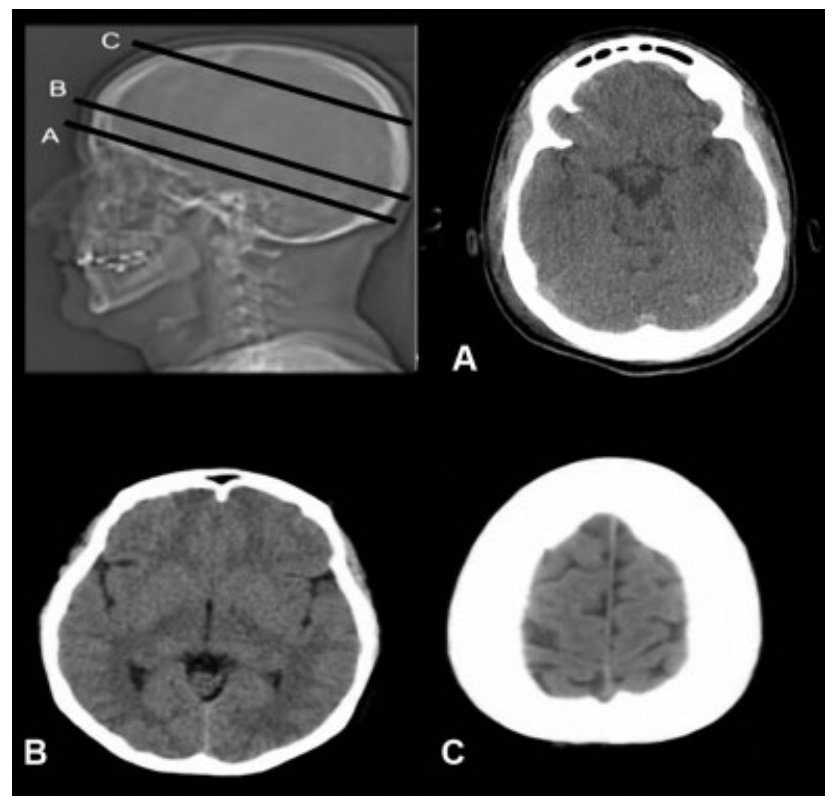

Fig. 1 Schematic evaluation of brain swelling after traumatic brain injury in computed tomography scans, assessing the anterior cisterns (A), the sylvian fissure/ambiens cistern (B) and the cortical sulci (C)

assured by anonymity of all patients, as identifications were kept confidential. All of the participants in the present study (the physicians evaluating the CT scans) agreed to make the evaluations voluntarily.

\section{Procedures}

All patients had undergone a skull $\mathrm{CT}$ in the same service using a CT750 HD Lightspeed 64-slice CT Scanner (GE Healthcare, Chicago, IL, USA). After downloading the key images from the image database, 12 evaluators with different back- ground and levels of experience observed the images according to the criteria described below. The criteria were explained to each professional individually and personally.

The evaluators were: three board certified neurosurgeons, three neurosurgery residents, three board certified radiologists, and three board certified intensivists. These evaluators were physicians of the hospital staff who agreed to participate in the study. Baseline data of the patients were retrospectively collected from the medical charts. The 12 evaluators were blinded for the clinical data on the medical charts and they evaluated the CT scans individually, without interference from other colleagues.

\section{Imaging Review}

The analysis should be performed based on a zero to sixpoint scale, created especially for the present study, which aims to quantify the degree of cerebral swelling after a severe brain injury using three tomographic slices, on three different levels: convexity cortical sulci, sylvian fissure/ambiens cistern, and anterior cisterns (-Fig. 1). For each level, the evaluators should assign zero points if the aspect was considered as normal, one point if the referred structure (cistern/sulci) was compressed, and two points if it was absent (-Figs. $\mathbf{2}$ and $\mathbf{3}$ ). Each participant was free to use as much time as he/she needed to evaluate the scans according to the new scales, as time was not previously set up.

\section{Statistical Analysis}

The Kappa coefficient was used to quantify the interobserver agreement between the reviewers. To verify the correlation coefficient and interpret the strength of agreement, a commonly cited scale proposed by Landis et $\mathrm{al}^{12}$ was adopted:

(a) Almost perfect agreement: 0.81 to 0.99 ;

(b) Substantial agreement: 0.61 to 0.80 ;

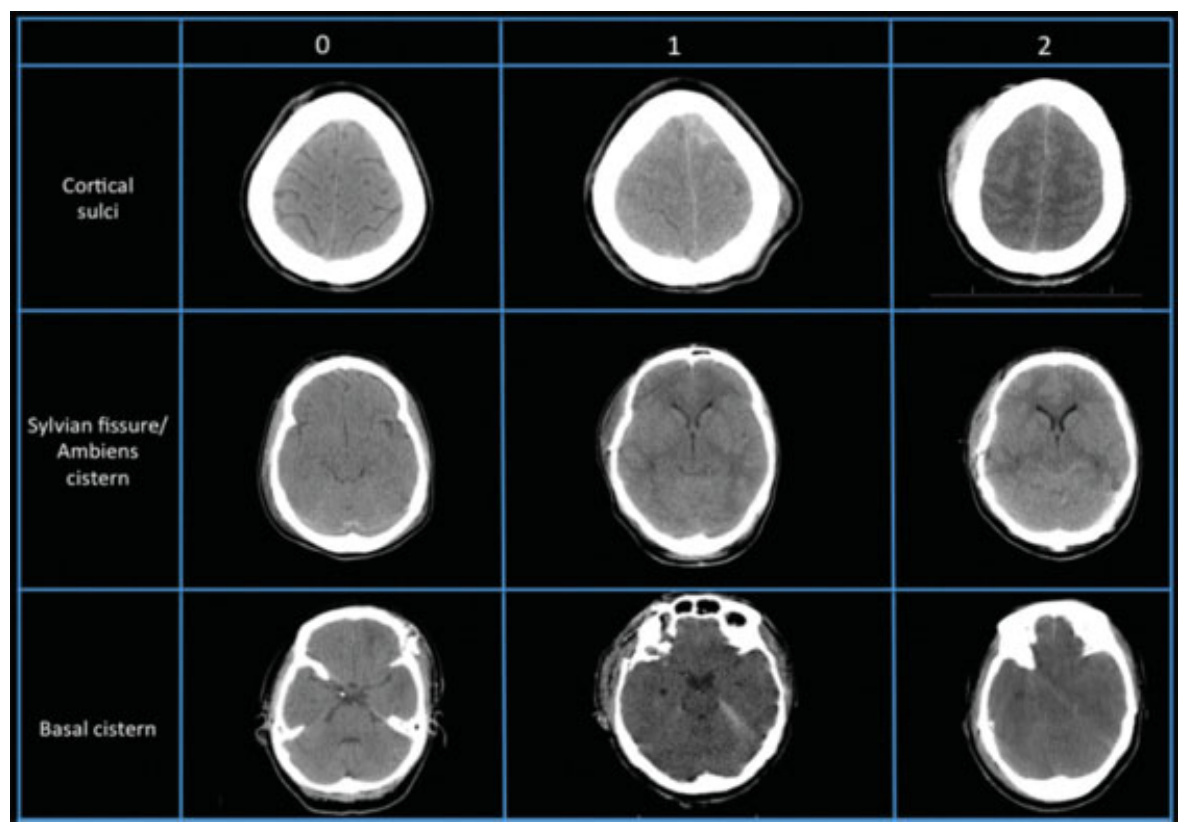

Fig. 2 Scoring system for the evaluation of brain swelling after traumatic brain injury in computed tomography scans: examples of scores 0,1 and 2 for the cortical sulci (first row), sylvian fissure/ambient cistern (second row) and anterior cisterns (third row) 


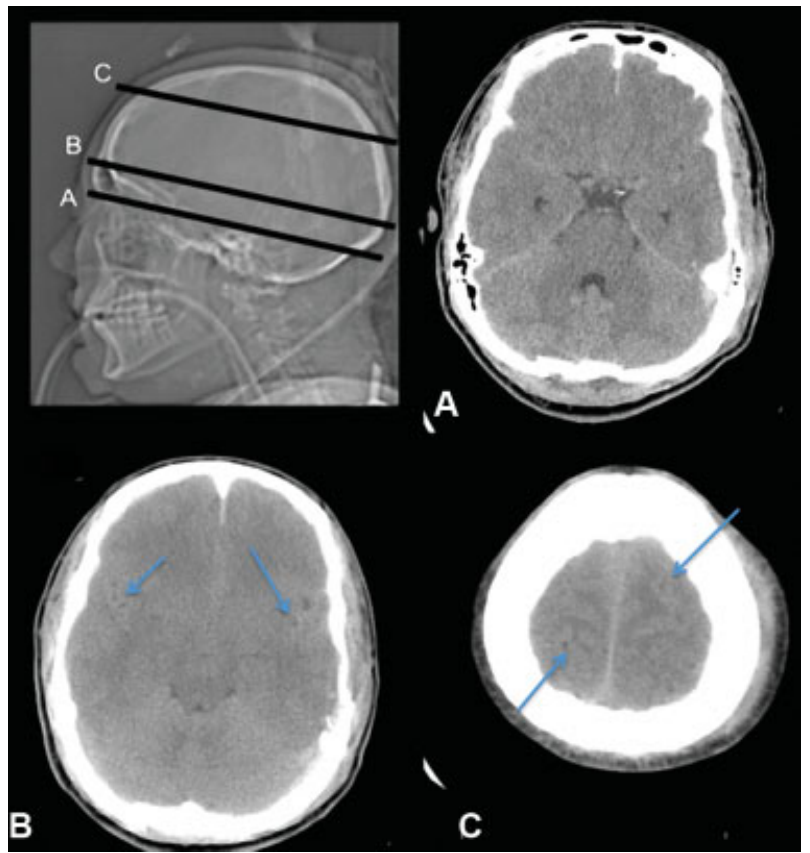

Fig. 3 Practical example of scale usefulness: computed tomography score of 2, due to compression of cortical sulci and sylvian fissure (one point each), and zero point at the lowest level (anterior cisterns), classified as normal.

(c) Moderate agreement: 0.41 to 0.60 ;

(d) Fair agreement: 0.21 to 0.40 ;

(e) Slight agreement: 0.01 to 0.20 ;

(f) Less than chance agreement: $<0$

\section{Results}

A total of 20 nonenhanced head CT scans of 20 patients sustaining closed TBI were randomly selected for the analysis in the study period. All of these 20 CT scans were evaluated by the 12 evaluators.

A total of 16 patients were male, and the average age was 40.3 years old. A total of 13 patients sustained high impact injuries, 6 were victims of fall, and 1 had an unknown mechanism of trauma.

The reliability evaluation of the scale in the neurosurgeons group was 0.791 (95\% confidence interval $[\mathrm{CI}]$ : $0.975-0.607 ; p<0.001$ ), classified as a substantial agreement according to Landis et al. ${ }^{12}$ In the neurosurgery residents group, the coefficient was 0.402 (95\%CI: 0.569-0.236; $p<0.001$ ), considered as a fair agreement. The radiologists showed also a fair agreement, with a correlation coefficient of 0.301 (95\%CI: $0.488-0.113 ; p=0.002$ ), and the lowest coefficient was found among the intensivists group (0.248; 95\%CI: $0.415-0.081 ; p=0.004)$, representing a slight agreement. Finally, the overall reliability showed a moderate agreement (0.503; 95\%CI: 0.549-0.457; $p<0.001$ ).

\section{Discussion}

The present study is, to our knowledge, the first aiming to evaluate the reliability of a classification system created to quantitatively qualify the level of brain swelling among TBI patients using CT scans and considering the convexity cortical sulci, the sylvian fissure/ambiens cistern, and the anterior cisterns. The proposed scale showed an overall moderate reliability, which makes it feasible to be used in clinical investigations.

Some studies have shown the potential role of CT in predicting outcomes (Impact, Niejemein models) ${ }^{13}$ considering the cortical sulci and the anterior cisterns. Other CT findings known as independent predictors of prognosis, such as midline shift or subarachnoid hemorrhage, were not used, since our main aim was to evaluate the amount of brain swelling and not the prognosis of an admission scale. We believe that the radiological scales to predict outcomes based on the admission CT findings were already adequately validated in different populations. However, these scales are not used in follow-up CT scans. For instance, there is no role of these validated scales on postoperative CT scans. As we aimed to evaluate the amount of brain swelling, we have also added the evaluation of the sylvian fissure/ambiens cistern.

The best result was found among neurosurgeons. This is probably related to the high number of TBI patients evaluated by the neurosurgeons and neurosurgery residents in everyday practice, as well as the extended time in which these professionals are responsible for monitoring these patients. The level of experience may also play a role and may have differentiated the results between the neurosurgeons and residents. However, we believe that, with proper training, it will be possible to obtain better results among different specialists. Considering the overall reliability of this scale, it may be used by different specialists who take care of TBI patients. The imaging features analysis may allow early identification of deterioration or improvement of brain swelling, which may be used as another tool when it's not possible to invasively measure the intracranial pressure. The diagnostic and prognostic value of the new scale should be further tested.

In the context of traumatic brain injury, the Rotterdam scale and the Marshall scale are useful tools that enable the gradation of trauma severity using imaging features, and they are equally useful to predict death in patients with TBI. ${ }^{14}$ The last one is the oldest and most common scale used to classify TBI. The Rotterdam CT score is a radiological scale often used to analyze the status of the basal cisterns on the initial CT scan; one or two points are added if the basal cisterns are compressed or absent, respectively. Studies have shown that effacement of the basal cisterns is a potential prognostic predictor; ${ }^{15}$ however, no data are available regarding the possible prognostic value of the sylvian fissure and cortical sulci status - which are now included in the new scale proposed here, which takes into account the basal cistern and also these two additional regions. Although not originally developed to be a scale to assess prognosis, high scores probably lead to a worse outcome, something that needs to be tested in future studies. Additional CT findings, such as hypointensities and signs of structural damages (hematomas, for instance, were excluded), were not taken into consideration. 
The implementation of standardized trauma care protocols in the initial approach of TBI patients has shown to decrease mortality. ${ }^{16}$ The existence of a scale that allows objective and longitudinal assessment of brain swelling in everyday neurointensive care is of major importance. None of the existing scales proposes such kind of longitudinal evaluation, which would be of great importance, especially in comatose patients without ICP monitoring. Critical care physician management of sedation weaning could be optimized and become safer using this brain swelling scale, which can be used in patients classified as Marshall I to III lesions and, although not tested, may also be used on postoperative CT scans. The objective of the present study, however, was not to find correlations between the imaging findings and the clinical status (Glasgow scales, clinical outcomes, etc.); rather, the present investigation sought to verify whether the evaluation could be done by professionals of different backgrounds. The beginning of a new investigation on the clinical usefulness of the new scale should be preceded by prior evaluation of the possible lack of interobserver agreement that would arise when professionals with different backgrounds would evaluate the same images. As shown in the present study, the agreement was moderate, and can possibly improve with proper training of some of the specialists.

One may argue that the present scale does not consider some relevant predictors, such as midline shift or presence of petechial lesions. However, the main purpose of this scale is to allow the comparison of tomographic features within the same subject, mainly in patients in whom it is not clear whether the brain swelling is ameliorating or worsening. Moreover, the presence of specific hematomas or midline shift is already a clear tomographic feature that can require surgical treatment or an emergency clinical treatment. For example, considering a patient with an acute subdural hematoma with midline shift, the decision of surgical treatment can be easily defined. However, in coma patients with Marshall II lesions at admission, not monitored by ICP, the decision on whether to maintain or not the sedation is not straightforward. Therefore, the proposed scale may assist clinical decisions in these patients. Of course, the longitudinal evaluation of such a scale should be tested in properly designed studies.

There are a few limitations in our study. First of all, our sample size is small, although it has been enough to show that the scale may be feasible to assess in the clinical setting. Second, we proposed a new scale among many other radiological scales already available and well-established, which might be confusing for the professional dealing with emergencies. However, the proposed scale may be used in every CT scan, making comparison feasible between the imaging studies. Third, the groups of physicians did not receive a formal training to use the scale, only individual guiding prior to the evaluations, which was simple and not standardized. Therefore, our findings indicate that the overall agreement may possibly be increased by properly planned training, with registering of the time taken for evaluations.

Finally, a definitive outcome, such as mortality or prognosis in 6 months, was not assessed. An assessment of prognosis could definitely stratify the degree of swelling in mild, moderate or severe, for instance. However, our main objective was achieved, since the findings about the scale reliability were statistically significant and represent preliminary data of a prospective study we intend to conduct, which will address these issues.

\section{Conclusions}

The scale proposed in the present study showed moderate overall reliability and a substantial agreement in the evaluations of the neurosurgeons. The overall reliability of the scale is acceptable for the daily practice in the emergency rooms and ICUs. The highest reliability strength was found among neurosurgeons, and the lower among the intensivists. The scale seems to be feasible to be applied, especially in patients whose intracranial pressure is not monitored by an implantable catheter. The importance of this scale relies on the idea that CT scans are widely available, even in low income countries, where ICP monitoring is costly. Further studies assessing the impact of formal training of the clinicians on the overall agreement and assessing the association of the scale results with clinical outcomes and prognosis are essential.

Conflicts of Interests

The authors have no conflicts of interest to declare.

\section{References}

1 Raj R, Skrifvars M, Bendel S, et al. Predicting six-month mortality of patients with traumatic brain injury: usefulness of common intensive care severity scores. Crit Care 2014;18(02):R60

2 Kraus JF. Epidemiology of Head Injury. In: Cooper Paul R., editor. Head Injury. Williams and Wilkins; 1993

3 Sosin DM, Sniezek JE, Waxweiler RJ. Trends in death associated with traumatic brain injury, 1979 through 1992. Success and failure. JAMA 1995;273(22):1778-1780

4 Unterberg AW, Stover J, Kress B, Kiening KL. Edema and brain trauma. Neuroscience 2004;129(04):1021-1029

5 Zimmerman RA, Bilaniuk LT, Genneralli T. Computed tomography of shearing injuries of the cerebral white matter. Radiology 1978; 127(02):393-396

6 Zimmerman RA, Bilaniuk LT, Bruce D, Dolinskas C, Obrist W, Kuhl D. Computed tomography of pediatric head trauma: acute general cerebral swelling. Radiology 1978;126(02):403-408

7 Liu H, Wang W, Cheng F, Yuan Q et al: External ventricular drains versus intraparenchymal intracranial pressure monitors in traumatic brain injury: a prospective observational study. World Neurosurgery 2014 Dec 23. pii: S1878-8750(14)01411-9.

8 Chesnut RM, Temkin N, Carney N, et al; Global Neurotrauma Research Group. A trial of intracranial-pressure monitoring in traumatic brain injury. N Engl J Med 2012;367(26):2471-2481

9 Marshall LF, Marshall SB, Klauber MR, et al. A new classification of head injury based on computerized tomography. J Neurotrauma 1992;9(Suppl 1):S287-S292

10 Maas AI, Hukkelhoven CW, Marshall LF, Steyerberg EW. Prediction of outcome in traumatic brain injury with computed tomographic characteristics: a comparison between the computed tomographic classification and combinations of computed tomographic predictors. Neurosurgery 2005;57(06):1173-1182, discussion 1173-1182

11 Marshall LF, Marshall SB, Klauber MR, et al. The diagnosis of head injury requires a classification based on computed axial tomography. J Neurotrauma 1992;9(Suppl 1):S287-S292 
12 Landis JR, Koch GG. The measurement of observer agreement for categorical data. Biometrics 1977;33(01):159-174

13 Majdan M, Lingsma HF, Nieboer D, Mauritz W, Rusnak M, Steyerberg EW. Performance of IMPACT, CRASH and Nijmegen models in predicting six month outcome of patients with severe or moderate TBI: an external validation study. Scand J Trauma Resusc Emerg Med 2014;22:68

14 Mata-Mbemba D, Mugikura S, Nakagawa A, et al. Early CT findings to predict early death in patients with traumatic brain injury: Marshall and Rotterdam CT scoring systems compared in the major academic tertiary care hospital in northeastern Japan. Acad Radiol 2014;21(05):605-611

15 Maas AI, Steyerberg EW, Butcher I, et al. Prognostic value of computerized tomography scan characteristics in traumatic brain injury: results from the IMPACT study. J Neurotrauma 2007;24 (02):303-314

16 Kesinger MR, Nagy LR, Sequeira DJ, Charry JD, Puyana JC, Rubiano AM. A standardized trauma care protocol decreased in-hospital mortality of patients with severe traumatic brain injury at a teaching hospital in a middle-income country. Injury 2014;45(09):1350-1354 